\title{
Article \\ Digital Geological Mapping to Facilitate Field Data Collection, Integration, and Map Production in Zhoukoudian, China
}

\author{
Chengbin Wang *, Xinqing Wang and Jianguo Chen
}

check for

updates

Citation: Wang, C.; Wang, X.; Chen, J. Digital Geological Mapping to

Facilitate Field Data Collection,

Integration, and Map Production in

Zhoukoudian, China. Appl. Sci. 2021,

11, 5041. https://doi.org/10.3390/

app11115041

Academic Editors: Antonio

Sarasa Cabezuelo, Santi Caballé and Jordi Conesa

Received: 14 April 2021

Accepted: 27 May 2021

Published: 29 May 2021

Publisher's Note: MDPI stays neutral with regard to jurisdictional claims in published maps and institutional affiliations.

Copyright: (c) 2021 by the authors. Licensee MDPI, Basel, Switzerland. This article is an open access article distributed under the terms and conditions of the Creative Commons Attribution (CC BY) license (https:// creativecommons.org/licenses/by/ $4.0 /)$.
State Key Laboratory of Geological Processes and Mineral Resources \& School of Earth Resources, China University of Geosciences, Wuhan 430074, China; wangxq@cug.edu.cn (X.W.); jgchen@cug.edu.cn (J.C.)

* Correspondence: wangchb@cug.edu.cn

\begin{abstract}
The development of innovative information technologies has improved the geological mapping process through the use of smart and portable equipment to collect field data, build a geological database and produce geological maps. This revolution has also brought great influence and challenges to practical training in field geology. In this paper, we present our workflow and application of the Digital Geological Survey System (DGSS) during field geology training for undergraduates in Zhoukoudian. The DGSS employs a Point-Routing-Boundary (PRB) model to reform the methods of geological section survey and geological mapping in terms of data collection and map-making and provides a pipelined solution from field data collection to map-making. The experiences of data collection, geological mapping, cross-section survey, and production of stratigraphic histograms and cross-section maps prove that DGSS can save time and reduce labor intensity for undergraduates during learning field geology. Based on the field practice of undergraduates in Zhoukoudian, the influence of the DGSS in promoting field geological teaching and the students' feedbacks to DGSS are discussed. Overall, the DGM system is more popular than the conventional notebook and toolbox. The experience in Zhoukoudian proves that digital devices are efficient and useful for geological practical training of field geology for undergraduates.
\end{abstract}

Keywords: digital geological mapping; field geological survey; PRB model; cross-section survey; Zhoukoudian; digital geological survey system

\section{Introduction}

Since the creation of the first detailed geological map by William Smith in 1815, geological mapping has had a long history [1]. In conventional map-making, a toolbox including a pencil, a Brunton compass, a hammer, lenses, a notebook, and sketch paper is used to collect field geological data. Although conventional geological mapping is labor-intensive, geologists have worked in that way for a long time. In the digital era, new frameworks, instruments, and software packages, such as digital compasses, digital cameras, Geographic Information System (GIS) and Global Positioning System (GPS), have great potential to improve and even change the way of geological mapping. In recent decades, the approaches of digital geological mapping (DGM) have attracted increasing global attention. Many computer scientists and geologists have worked together to build a data framework of DGM and develop hard- and software systems to facilitate field geological survey and education [2-15].

Initiatives of DGM started in the 1980s. Due to the incomplete or ambiguous records by different geologists in the field at the data collection stage, some geological codes and principles were designed to standardize field data entry into a computer for producing digital geological maps and databases [16,17]. Then, since the 1990s, field software systems of DGM have been developed, such as ArcPad-ArcGIS systems [5], GSMCAD FieldPad [18], MapIT [8,10,19], GeoMapper (PenMap) [3], FieldLog [20], FieldBook [21], Natmap [22], iGIS [23], the Digital Geological Survey System (DGSS) [24-26], and palmtop-based RDBMS and SIGMA systems [15], and tested for geological mapping in Europe, Australia, China, 
and North America. DGM development also led to discussions on the selection of hardware devices between Personal Digital Assistants (PDAs) and Tablet computers [9,27]. In recent years, Android tablets and iPads have been widely popular, and some apps (e.g., FieldMove, StraboSpot, AoRGMAP, etc.) supporting field data collection have been developed and applied in geological mapping [28-31].

DGM technology has not only changed the way of data collection and mapping in the industry but has also had a deep influence on the geological practice of undergraduates in the field [30-33]. The DGSS developed by the Development and Research Center of China Geological Survey provides a pipelined solution for field data collection, data compilation, mapping, and data sharing in the industry based on a shared data flow. The DGSS includes the basic GIS platform DGSGIS, the desktop data processing system DGSInfo for field data, a geodata adjustment system, and the field data collection system AoRGMAP in the handheld equipment [24-26]. DGSInfo and DGSGIS are desktop software running on the Windows system (Win7 and later). AoRGMAP is a free app that can run on a PDA or smartphone with an Android system to collect field data. Although AoRGMAP can run on smartphones, there is a great accuracy difference between smartphones and customized PDA in terms of the digital compass and positioning system [33,34]. A customized PDA is the preferred hardware for using AoRGMAP in industry application and field geological teaching. The DGSS has been used in the field of geological practice of undergraduates of China University of Geoscience (Wuhan) for a decade in Zhoukoudian, China [35,36]. Although a lot of works about DGM and its application in geological education have been documented, most of them were reported in Chinese rather than in English, which made those latest works less visible to the global community.

In this paper, based on the experiences in Zhoukoudian, China, we introduce the applications of the DGSS in the field geology practice of undergraduates in terms of field data collection, data integration and processing, and geological map production. The remainder of the paper is organized as follows. In Section 2, we introduce the geological setting and related background of this study. In Section 3, we present the methods used in the DGSS in terms of data collection, data integration, and map production. In Section 4, we present the result of digital geological mapping, a cross-section geological survey carried by undergraduates in Zhoukoudian. In Section 5, The influence of DGSS in promoting field geological teaching and the students' feedbacks to DGSS are discussed. Finally, in Section 6, several conclusions are drawn based on this study.

\section{Background and Geological Setting}

The Zhoukoudian practical training base is located $50 \mathrm{~km}$ southwest of Beijing and is adjacent to the famous Peking Man site. It is an important part of the Fangshan UNESCO Global Geopark. The first geological research in the Zhoukoudian area was conducted in 1867 [37], and the first geological training session was held in 1914. In 1954, Professor Xingyuan Ma and geologists from the former Soviet Union built the practice base. Since then, has trained tens of thousands of Chinese geological undergraduates and international students, being praised as "The Cradle of Geologists".

The Zhoukoudian area is located in the North China Craton (NCC) and has a long geological evolutionary history from the Archean eon. Most of the typical strata, geological structures, and magmatic activities occurring in North China can also be found in this small area, which provides abundant teaching resources (Supplement Table S1) for practical training of field geology of undergraduate geological practice in the field. The oldest basement rocks are the Guandi complex of amphibolite facies with an age of ca. $2.5 \mathrm{Ga}$ and intruded by the early Cretaceous Fangshan pluton dated at ca.133 Ma [38]. In the middle Proterozoic, the Zhoukoudian area was in the sedimentary of coastal shallow sea and shallow sea and formed a series of sedimentary sequences of slate and dolomite. There is a sedimentary discontinuity between the overlaying Xiamaling Formation $\left(\mathrm{Pt}_{2} x\right)$ and Tieling Formation $\left(\mathrm{Pt}_{2} t\right)$. An uncomfortable boundary also occurs between Neoproterozoic and middle Proterozoic strata. In the early Paleozoic, sedimentary sequences of limestone, slate, oolitic limestone, 
and dolomite were formed in the tidal flat-coastal shallow sea environment. The upper Paleozoic strata include chlorite hornstone, andalusite hornstone, limestone, slate, siltstone, quartz sandstone, slate intercalated coal seam, and breccia. The intrusion of the Fangshan pluton produces thinned strata contacted by faults and thermal metamorphism. Magmatic flow structures, ductile and brittle structures (e.g., S-C fabric, rotating porphyroblasts, domino structure, and mylonite), and lithofacies zonation occur in the Fangshan pluton. Regional tectonic and plutonic intrusion also produced geological structures, such as regional and small-scale faults, different types of fold deformation, and derivative structures (e.g., cleavage). In addition, there is also a geological tourist route at Shidu in the geopark for undergraduates to explore and learn independently.

In the geological education system in China, four-year university education can be divided into four stages according to the curriculum. For the major of Exploration Engineering of Mineral Resource, the courses in the first stage mainly include fundamental courses (e.g., mathematics, computer programing, physics, and chemistry) and an introduction to physical geology. After the first stage indoor education, field geological cognition training without too overly professional knowledge will follow for the freshmen. In the second stage, the undergraduates are taught petrology, mineralogy, paleontology, stratigraphy, and structural geology. The DGM system is used during field training for undergraduates who have completed the above courses. In the third stage, some courses associated with mineral deposits and mineral exploration will be listed in the class schedule. In the last stage, the courses mainly include mineral resource mining, mineral resource economics, and mineral processing.

Before a four-week field training in Zhoukoudian, sophomore undergraduates will have a two-credit indoor course to learn the basic theory and operation of the DGM system. During field training in Zhoukoudian, a class of 20-25 undergraduates is equipped with two instructors, and the whole class is divided into groups with five undergraduates each. Every group is equipped with one PDA with a DGM system. The field training includes two stages. In the early stage, instructors show and describe the geological features in the field outcrops and guide the undergraduates to observe the geological features and think about their origins. At this stage, the PDA devices with the DMG system are rarely used by undergraduates. In the late stage, based on the understanding of the geological background in the first stage, regional geological mapping and geological section surveys are carried out by every group. Each group needs to cooperate to complete a digital geological survey at areas $\mathrm{A}$ and $\mathrm{B}$ (Figure 1) according to the data collection specifications in the field using PDA with the AoRGMAP. 


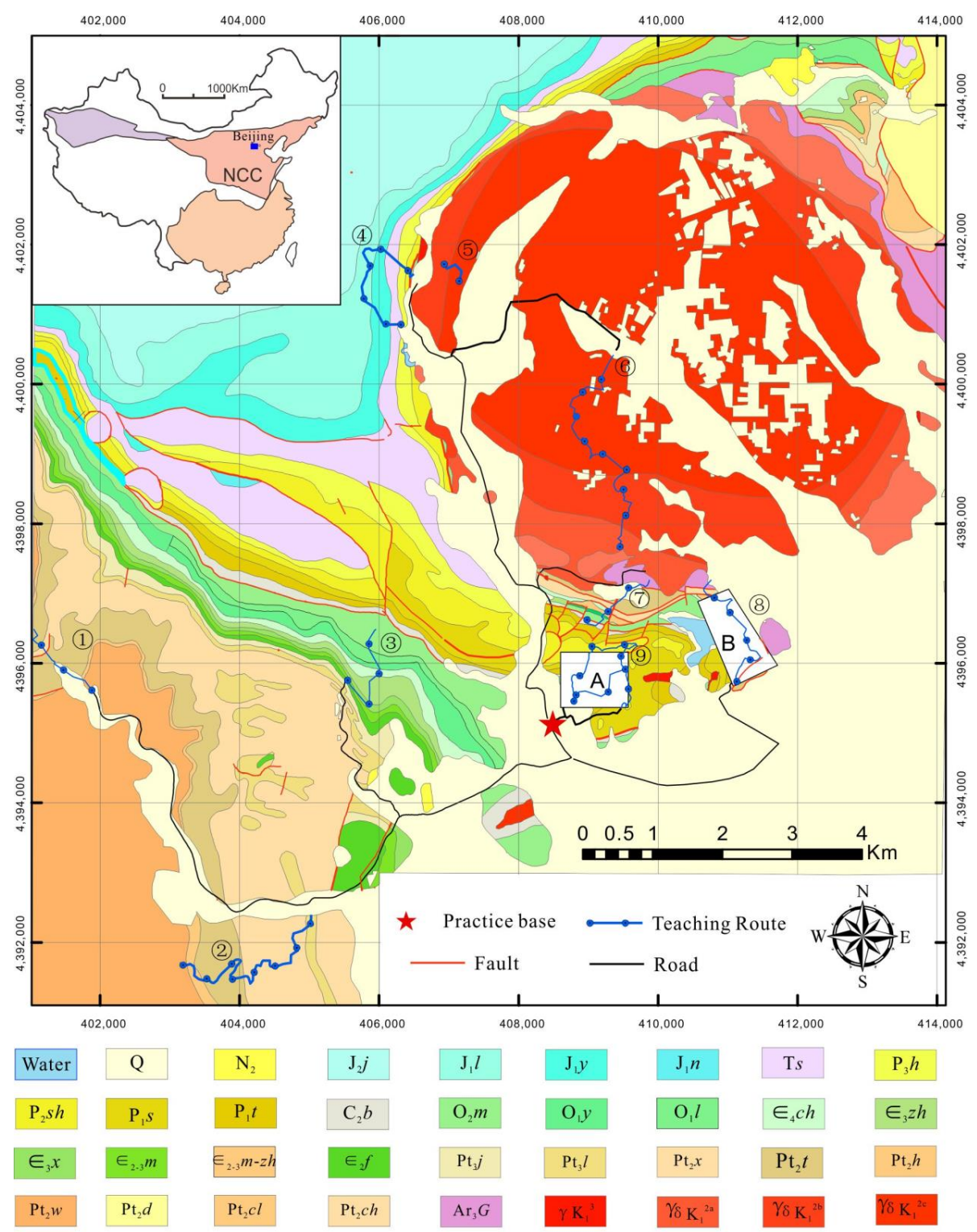

$\delta \mathrm{oK}_{1}$

Figure 1. The main teaching resources distributed in the Zhoukoudian area. Teaching route: (1) Overturn and thinning of Meso-Neoproterozoic strata and microstructure. (2) Regional metamorphism and Meso-Neoproterozoic strata.(3) Lower Paleozoic strata, fold-related structure.(4) Jurassic river/lake sedimentary sequences and coal-bearing strata.(5) Brittle and ductile structures caused by the intrusion of the Fangshan pluton.(6) Intrusive lithofacies zonation of the Fangshan pluton.(7) Guandi core complex of amphibolite facies, fault-related strata thinning, and thermodynamic metamorphism. (8) Strata thinning and reverse fault. (9) Upper Paleozoic strata and fold. Strata: Q: Quaternary; N2: Neogene; J2j: Jiulongshan Formation; $\mathrm{J}_{2} l$ : Longmen Formation; $\mathrm{J}_{1} y$ : Yaopo Formation; $\mathrm{J}_{1} n$ : Nandaling Formation; Ts: Shuangquan Formation; $\mathrm{P}_{3} h$ : Hongmiaoling; $\mathrm{P}_{2}$ sh: Shihezi Formation; $\mathrm{P}_{1}$ s: Shanxi Formation; $\mathrm{P}_{1} t$ : Taiyuan Formation; $\mathrm{C}_{2} b$ : Benxi Formation; $\mathrm{O}_{2} m$ : Majiagou Formation; $\mathrm{O}_{1} y$ : Yeli Formation; $\mathrm{O}_{1} l$ : Liangjiashan Formation; $\epsilon_{4}$ ch: Chaomidian Formation; $\epsilon_{3} z h$ : Zhangxia Formation; $\epsilon_{3} x$ : Xuzhuagn Formation; $\epsilon_{2-3} m$ : Mantou Formation; $\epsilon_{2-3} m-Z h$ : Mantou-Zhangxia Formation; $\epsilon_{2} f$ : Fujunshan Formation; $\mathrm{Pt}_{3} j$ : Jingeryu Formation; $\mathrm{Pt}_{3} l$ : Longshan Formation; $\mathrm{Pt}_{2} x$ Xiamaling Formation; $\mathrm{Pt}_{2} t$ : Tieling Formation; $\mathrm{Pt}_{2} h$ : Honshuizhuang Formation; $\mathrm{Pt}_{2} w$ : Wumishan Formation; $\mathrm{Pt}_{2} d$ : Dahongyu Formation; $\mathrm{Pt}_{2} c l$ : Chuanlingou Formation; $\mathrm{Pt}_{2}$ ch: Changzhougou Formation; $\mathrm{Ar}_{3} \mathrm{G}$ : Guandi core complex. 


\section{Method}

\subsection{Pipelined Digital Geological Mapping System}

From field collection to geological mapping, data need to be exchanged between different hardware and programs. An important criterion for evaluating a digital geological mapping system is that data should not need any transformation in the data flowing between different modules. In the DGSS, according to the industry requirement, digital geological mapping is divided into modules of base map preparation; indoor design of the geological survey route; field data collection; data cleansing and modification; PRB (PointRoute-Boundary) database; primitive map, and geological map compilation, and geological map database. Moreover, the DGSS also supports the logging of the cross-section for making geological cross-section maps and stratigraphic histograms.

Unified data formats (Figure 2) are designed for data flow in different modules and hardware equipment. Vector data are divided into three types: point, polyline, and polygon. The geometrical information of geological features is stored in spatial feature files (e.g., ${ }^{*} . \mathrm{tm},{ }^{*} . \mathrm{lm},{ }^{*} . \mathrm{pm}$ ), while properties of geological features are stored in SQLite database files (e.g., * ta, *.la, *.pa). All the files of point, polyline, and polygon are organized by a project index $\left({ }^{*}\right.$.gpj). This way, the data can be processed by different modules without any data transformation and provides a base data format for the pipelined digital geological mapping system. In addition, the DGSS can also input raster and image data as the base map.

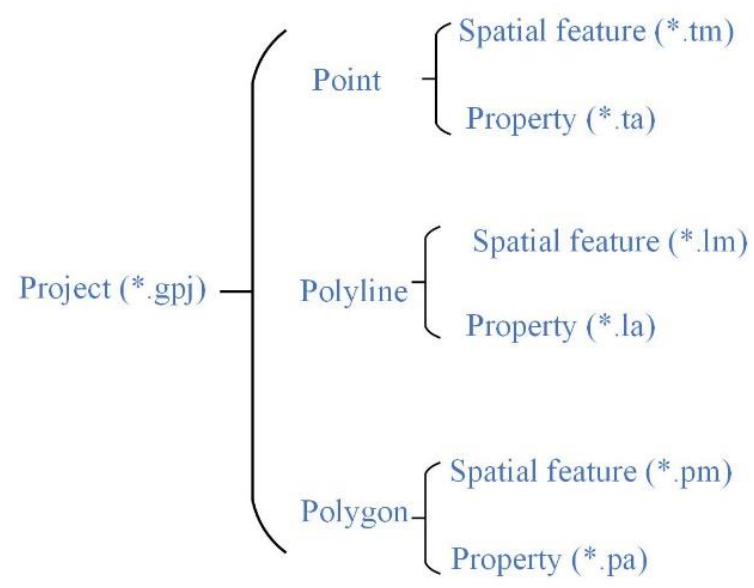

Figure 2. The vector data structure in the DGSS.

\subsection{The PRB Model for Field Data Collection}

Due to the complex field environment, DGM has high requirements for the field data collection system in terms of the device, software, battery life, portable display, and interactivity. The existing techniques are not able to satisfy all of the above requirements in a small handheld PDA, so it is necessary to develop a compromise between them. Simplicity and ease of use are important criteria for designing a field data collection system [5]. As polygon objects are difficult to input accurately in the field and further edit indoors, point and polyline objects are preferred as the forms for data entry in the field data collection. To address this issue, the Point-Routing-Boundary (PRB) model was proposed based on the process of geological survey in the field [39].

In the PRB model (Figure 1), the core $\boldsymbol{P}$ points represent the entity nodes to connect geological survey routes and collect information (properties). The $\boldsymbol{R}$ lines do not only record the field route track of the geological survey but also represent the segment linking between points and (or) boundaries. Thus, the $R$ lines between boundaries usually represent a unique geological unit, which can be used to automatically fill the unit properties of polygonal geological bodies in the stage of map-making. The $\boldsymbol{B}$ lines represent the explicit boundary between the geological units and provide implicit topological informa- 
tion between geological bodies, such as the properties of the geological unit and contact relationships.

In the PRB model, the $\boldsymbol{B}$ and $\boldsymbol{R}$ lines depend on the $\boldsymbol{P}$ points. Additionally, the $\boldsymbol{B}$ lines depend on the $\boldsymbol{R}$ lines. The life cycle of a $\boldsymbol{P}$ point starts from $\boldsymbol{P}_{\mathrm{n}}$ and ends up at $\boldsymbol{P}_{\mathrm{n}+1}$ (Figure 3e). A geological survey route can be regarded as a combination of PRB elements. $\boldsymbol{P}$, $\boldsymbol{R}$, and $\boldsymbol{B}$ elements can be flexibly combined according to the needs for a geological survey. The number of $\boldsymbol{R}$ and $\boldsymbol{B}$ lines is determined based on the complexity of a geological route. In a field geological survey, the $\boldsymbol{P}$ point can also be used alone for field data collection in outcrops (Figure 3a). The two $\boldsymbol{P}$ points can be connected by the $\boldsymbol{R}$ line to represent two geological survey points and the routing line from $\boldsymbol{P}_{\mathbf{1}}$ to $\boldsymbol{P}_{\mathbf{2}}$ (Figure $3 \mathrm{~b}$ ). As the pre-designed geological survey route is perpendicular to the strike of the geological framework, $P, R$, and $\boldsymbol{B}$ are always combined to represent a geological survey route (Figure $3 \mathrm{c}$ ), the point combined with a boundary to represent the geological boundary between two geological units, and the boundary on the routing $R$ line can be used to represent the boundary within the geological unit. Moreover, the PRB model can represent the intersection of multiple geological units (Figure 3d).

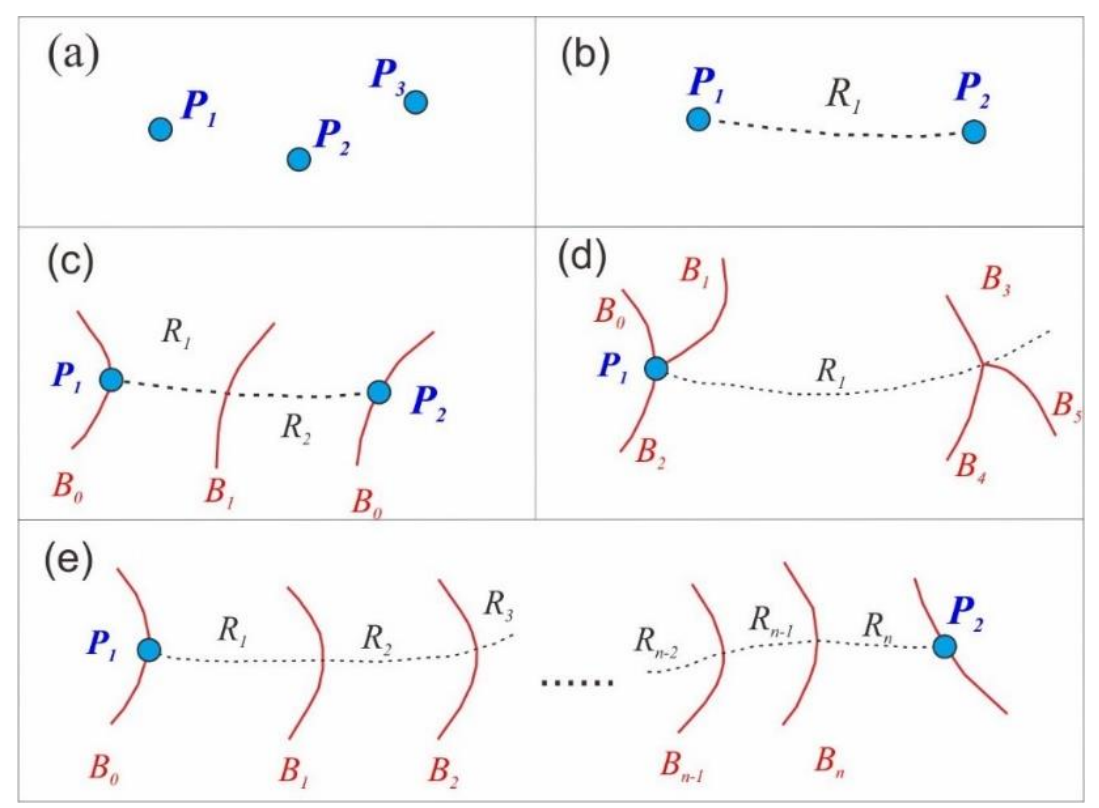

Figure 3. The conceptual pattern of the PRB model (modified from [39]). (a) The combination of $\boldsymbol{P}$ points. (b) The two $\boldsymbol{P}$ points connected by a $\boldsymbol{R}$ line. (c) A simple combination of $\boldsymbol{P}, \boldsymbol{R}$, and $\boldsymbol{B}$ elements. (d) PRB model represents the intersection of multiple geological units. (e) Life cycle of a $\boldsymbol{P}$ point and encoding rules of $\boldsymbol{R}$ and $\boldsymbol{B}$ lines. $\boldsymbol{P}$ points build the framework of the PRB model, and some important information (e.g., lithology, photos, attitude, structure, geological boundary, field route, etc.) from observations in the field is linked with the $\boldsymbol{P}$ points. $\boldsymbol{B}$ lines define the boundaries between geological bodies crossed by the survey route. $R$ lines record the geological survey track. Each $R$ line usually represents the geological unit that it goes through.

The PRB model constitutes a data framework for geological route surveys. Other information such as samples, attitudes, fossils, photos, and sketches can be added nearby and attached to the corresponding PRB elements based on the ID number.

\subsection{Field Data Collection of Geological Mapping}

A handheld Android device with AoRGMAP (Supplement App S1) can be used for field data collection for geological mapping. The user interface of AoRGMAP is shown in Figure 4a. The buttons of $P R B$, attitude, photo, sample, sketch, and fossil are listed on the top of the screen. The GPS button is displayed in a floating window (Figure 4a), which can be used for positioning to obtain the localities of geological points and other features. It can be 
hidden during data input to reduce distractions. Take the $\boldsymbol{P}$ point as an example-clicking the $\boldsymbol{P}$ button activates the interface (Figure $4 \mathrm{~b}$ ) for typing information in the field. All of the geological information (Table 1) can be collected in the field in a similar way.

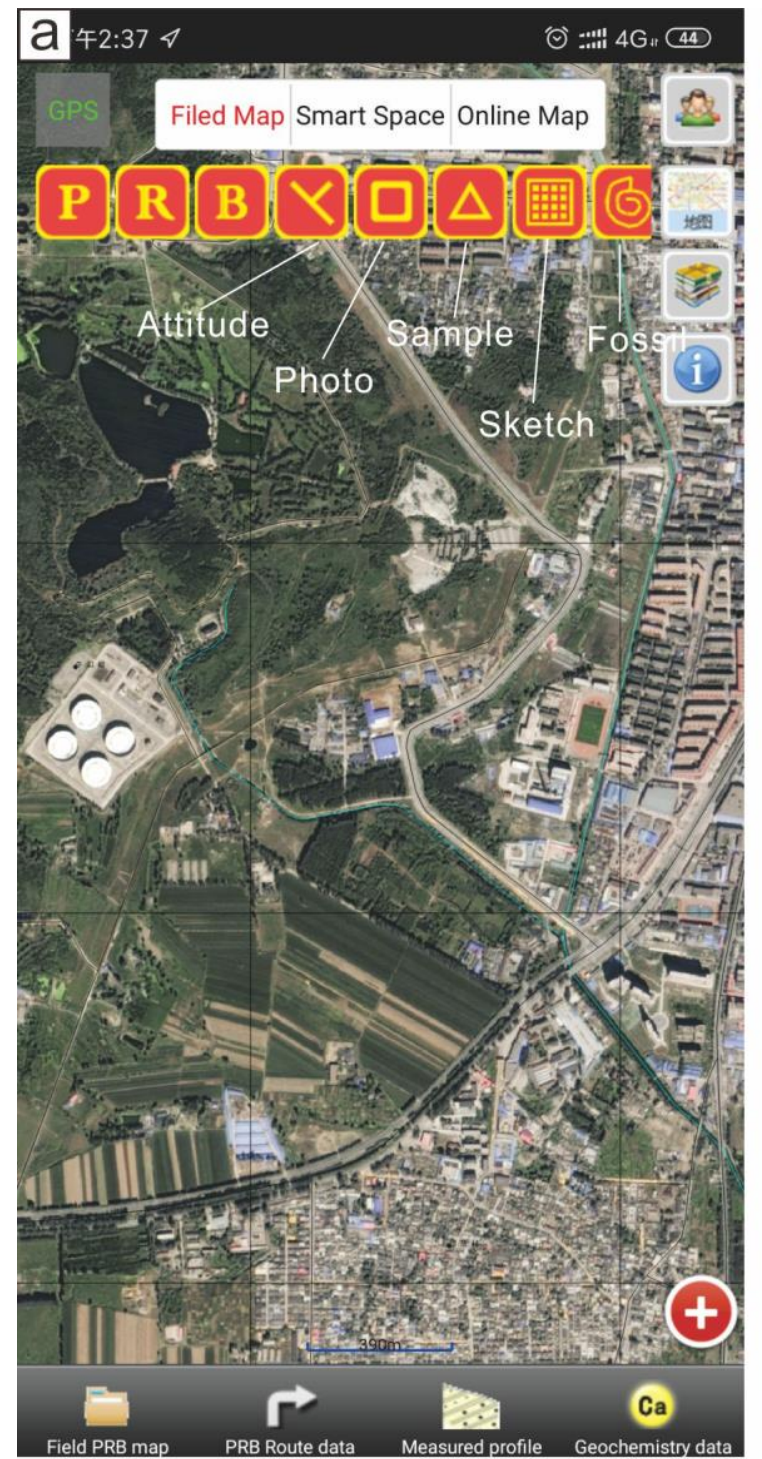

Figure 4. The user interface of AoRGMAP. (a) the base map and main buttons for field data collection; (b) the properties contained in the $P$ point.

The properties in AoRGMAP can be classified into three types: numeric data, terminology, and unstructured data. The numeric data include ID numbers, coordinates, attitudes, and spatial information (e.g., distance and direction). The coordinates, attitude, and spatial information can be acquired using a digital compass and GPS-based techniques. The properties associated with geological terminology can be inputted by selecting the options provided by a dictionary of the geological units, rock names, and contact relations. The unstructured data include photos, audio, videos, text descriptions, and sketches. In the geological notes (Figure 4b), geologists can type the text to describe the geological features of outcrops. In the PRB system, the photo information depends on the $\boldsymbol{P}$ points by sharing some key fields. To input photo information, the square icon (Figure 4a) should be clicked to activate the input interface, as shown in Figure $4 \mathrm{~b}$. In this interface, the PDA's camera can be used to take photos through the button commands. In this process, information 
about the camera orientation, photo number, coordinate, description, and affiliation can be added using automatic and manual methods. The photos taken in the field are stored in a specific folder and encoded automatically. Attitude, fossil, and sample information is also collected similarly in the field survey.

Table 1. The property types for field geological data collection in the AoRGMAP system.

\begin{tabular}{|c|c|}
\hline Type & Property Information \\
\hline Geopoint $(P)$ & $\begin{array}{l}\text { Route ID, Geopoint }(P) \text { ID, Coordinates }(X, Y) \text {, } \\
\text { Geographic coordinates, Z (Elevation), Location, } \\
\text { Microrelief, Geopoint feature, Outcrop, Weathered, } \\
\text { Mapping unit A, Rock name A, Mapping unit B, Rock } \\
\text { name B, Mapping unit C, Rock name C, Contact relation } \\
\text { A/B, Contact relation A/C, Contact relation B/C, } \\
\text { Geological note }\end{array}$ \\
\hline Routing $(R)$ & $\begin{array}{l}\text { Route ID, Geopoint }(P) \text { ID, Routing }(R) \text { ID, } \\
\text { Direction(degree), Distance, Cumulative distance, } \\
\text { Mapping unit, Rock name, Geological note }\end{array}$ \\
\hline Boundary $(B)$ & $\begin{array}{l}\text { Route ID, Geopoint }(P) \text { ID, Boundary }(B) \text { ID, Boundary } \\
\text { (B) type, Routing }(R) \text { ID, Contact relation, Left Mapping } \\
\text { unit, Right unit, Dip angle, Strike, Dip, geological note }\end{array}$ \\
\hline Attitude & $\begin{array}{l}\text { Route ID, Geopoint }(P) \text { ID, Coordinates }(X, Y) \text {, } \\
\text { Geographic coordinate, Routing }(R) \text { ID, ID, Dip Angle, } \\
\text { strike, dip, Attitude type, Mapping unit, Joint/Gravel } \\
\text { measuring data capture }\end{array}$ \\
\hline Photo & $\begin{array}{l}\text { Route ID, Geopoint }(P) \text { ID, Coordinates }(X, Y) \text {, } \\
\text { Geographic coordinate, Routing }(R) \text { ID, Photo ID, Photo } \\
\text { content, Serial number, Total number, Audio ID, Video } \\
\text { ID, Photo note }\end{array}$ \\
\hline Sample & $\begin{array}{l}\text { Route ID, Geopoint }(P) \text { ID, Coordinates }(X, Y) \text {, } \\
\text { Geographic coordinate, Z (Elevation), Routing }(R) \text { ID, } \\
\text { Sample ID, Sample content, Serial number, Total } \\
\text { number, Audio ID, Video ID, Sample note }\end{array}$ \\
\hline Sketch & $\begin{array}{l}\text { Route ID, Geopoint ID, Coordinate (X, Y), Geographic } \\
\text { coordinate, Routing (R) ID, Sketch ID, Sketch name, } \\
\text { sketch scale, sketch (Vector), Sketch (Grid), photo of a } \\
\text { sketch }\end{array}$ \\
\hline Fossil & $\begin{array}{l}\text { Route ID, Geopoint ID, Coordinates (X, Y), Geographic } \\
\text { coordinates, Routing ( } R \text { ) ID, Sample ID, Fossil class, } \\
\text { sampling horizon, sampling location, sampling person, } \\
\text { sampling data, fossil type. }\end{array}$ \\
\hline
\end{tabular}

AoRGMAP provides three ways to record field sketch maps: vector, grid, and photo. In the vector way, a geologist needs to draw points, polylines, and polygons on the screen to constitute the sketch. The grid method uses a brush to sketch on the grid screen. The width and color of the brush can be set according to requirements. In this way, the photo of geological outcrops can be input as a background for geological feature annotation. If the above methods cannot satisfy the needs, the geologist can also draw a sketch map in the paper and input a digital photo of the sketch into the system.

\subsection{Field Data Processing, Storage, and Map-Making}

The field data collected by AoRGMAP in a handheld device can be exported into DGSInfo (Supplement App S1) to build a PRB database for further processing of geological map-making. Most of the time, the raw data collected in the field may have some data missing, errors, and irregular shapes of PRB elements. A data cleansing step is necessary, such as editing the shape and location of PRB points and polylines using the graphic editing tools in DGSInfo and replenishing and proofreading the missing and incomplete 
information. The preprocessed data are then used to build a PRB database, which includes all of the geological route data collected in the field.

The PRB database is the original data source for producing different types of geological maps and geological databases. According to geological rules, a list of $\boldsymbol{B}$ lines can be connected as a geological boundary line separating two geological units. The polygon of a geological unit can be obtained by polygonizing and processing the geological boundary lines (Figure 5a). The properties of a polygon can be extracted from the corresponding $\boldsymbol{R}$ lines by spatial analysis between the polygon and the $R$ lines (Figure $5 b$ ). After finishing the primitive map, it can be projected on a specific scale to make a geological map and for building a map product database.

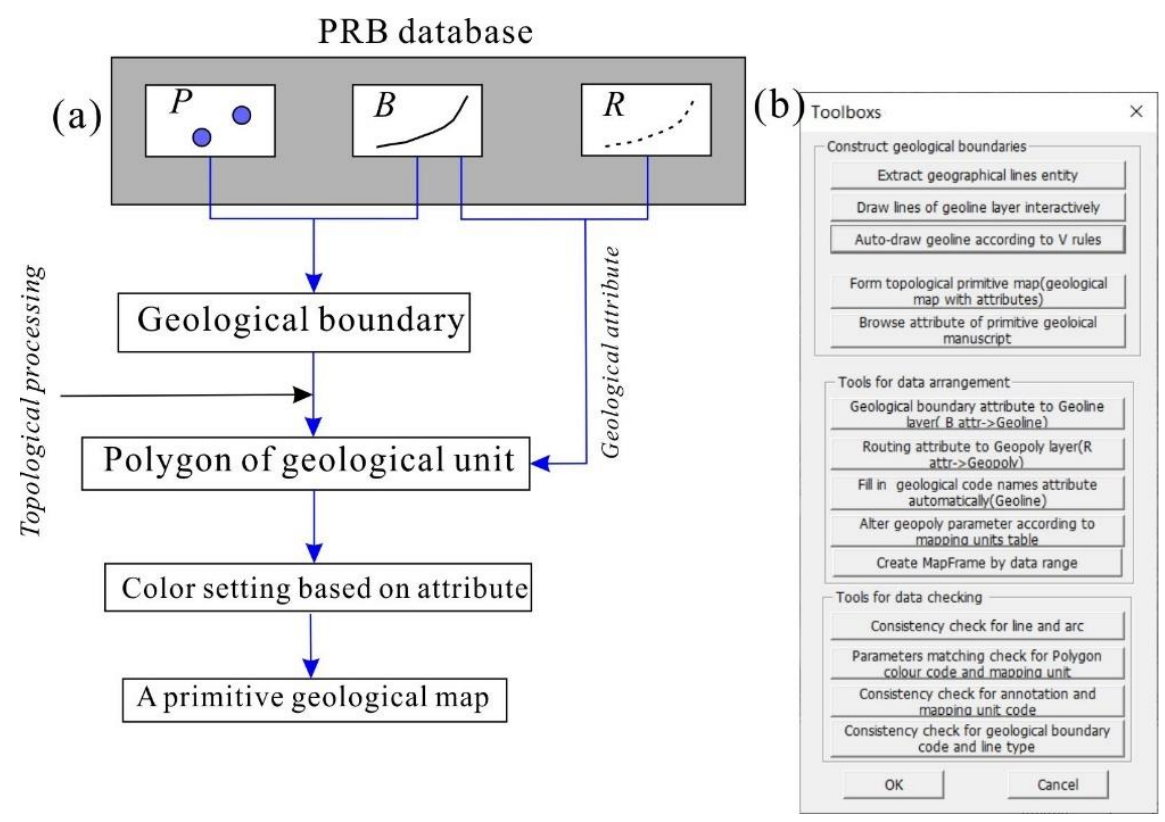

Figure 5. (a) The workflow of producing a primitive map based on the PRB database. (b) The toolbox used in the map-making process based on the PRB data.

\subsection{The Measurement of Geological Cross-Section}

In geological mapping, measuring and describing the stratigraphic division are important parts of the field effort to provide a reference for regional geological mapping in terms of stratigraphic division and lithological identification. In conventional training, at least four undergraduates are required to collaborate to perform the cross-section measurement. Two of them use a compass and measuring tape to measure the topographical profile using the broken open transverse method. Another student distinguishes the strata and measures the bedding orientations, and the last one records the observations in a paper notebook and table. After the fieldwork, students are asked to calculate several parameters (e.g., horizontal distance, slope angle, azimuth angle, etc.) and draw a cross-section map on grid paper using a pencil.

Imitating the conventional method of measurement of geological cross-section, AoRGMAP in the PDA is equipped with a digital compass, and the high-precision positioning system reforms the method of geological cross-section survey according to the important parameters required for a geological cross-section map. The high-precision differential positioning replaces the measuring tape to obtain the three-parameter coordinates (i.e., longitude, latitude, and elevation) and the derived orientation parameters of transverse (e.g., slope, distance, and azimuth). The digital compass in the PDA can acquire attitude information of strata and some geological structures. In this study, the Qmini A5 PDA made by Hi-Target was used to collect data. A digital compass, gravity sensor, barometer, and positioning system are embedded in the Qmini A5 PDA. The positioning method of the Qmini A5 PDA used in the field is a hybrid method combining GPS, BeiDou, GLONASS, SBAS (Satellite-Based Augmentation System), and AGPS 
(Assisted Global Positioning System). The BeiDou ground-based augmentation system can improve the positioning precision to $0.5 \mathrm{~m} \mathrm{[40]}$.

AoRGMAP obtains traverse and strata layering information and stores them in a table (Figure $6 \mathrm{a}, \mathrm{b}$ ). The strata layer and related measurements of geometric parameters are dependent on the traverse line (Figure $6 \mathrm{c}$ ). The input interface of traverse line and strata layering (Figure $6 \mathrm{~b}, \mathrm{~d}$ ) can be activated by the Add button (Figure $6 \mathrm{a}, \mathrm{c}$ ). The information of coordinates, azimuth angle, slope angle, and slope distance can be obtained by the positioning system and digital compass in the PDA. Furthermore, some other related data (e.g., photos, sample, fossil, and attitude) can also be added to enrich the cross-section information. Following the data collection in the field, the data are loaded into DGSInfo. Further data cleansing and modification were available to build a complete database (Figure 6e). Then, a cross-section map and stratigraphic histograms can be generated by DGSInfo automatically.

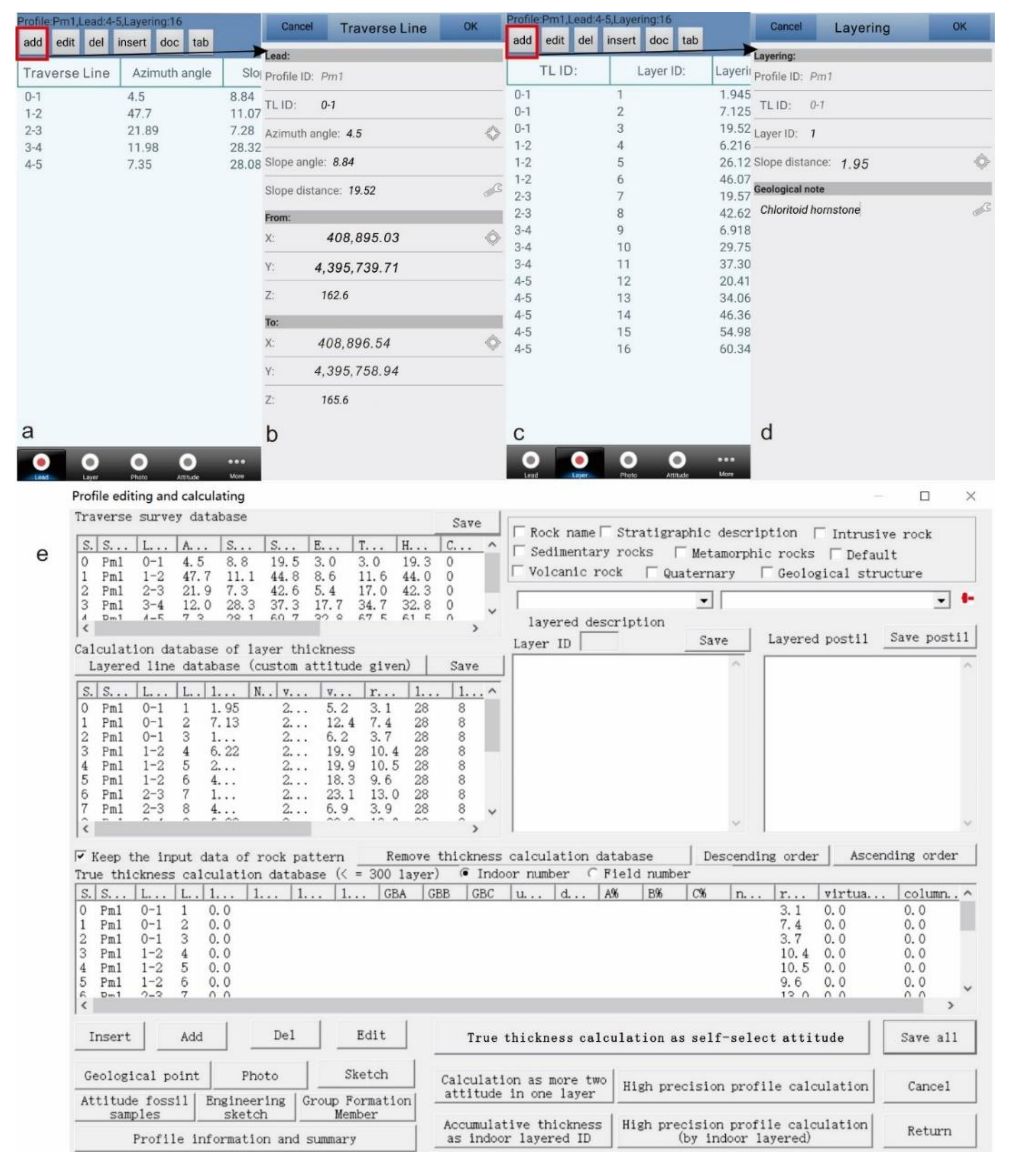

Figure 6. Traverse information collection in AoRGMAP. (a) The traverse information table in a geological section survey; (b) the traverse property interface. The star symbol indicates the parameter can be obtained automatically; (c) the stratum information table depending on the traverse information; (d) some properties of a stratum. (e) data processing of cross-section data in the desktop system of the DGSInfo system.

\section{Results}

\subsection{A Comparison between Digital Compass and Brunton Compass}

A comparison between a digital compass and a Brunton compass was run in the field. In total, 12 sets of data were collected by the same device and a Brunton compass. The PDA device used for attitude collection was the Qmini A5 PDA. Most errors in dip angles between the two types of compasses were less than $2^{\circ}$ (Figure 7 ). There was a $5^{\circ}$ gap in the dip direction between the digital compass and the Brunton compass (Figure 7), which is related to the magnetic declination and caused by lack of correction for the digital 
compass. The performance of the digital compass proves that it can be used for field data collection in a geological survey.
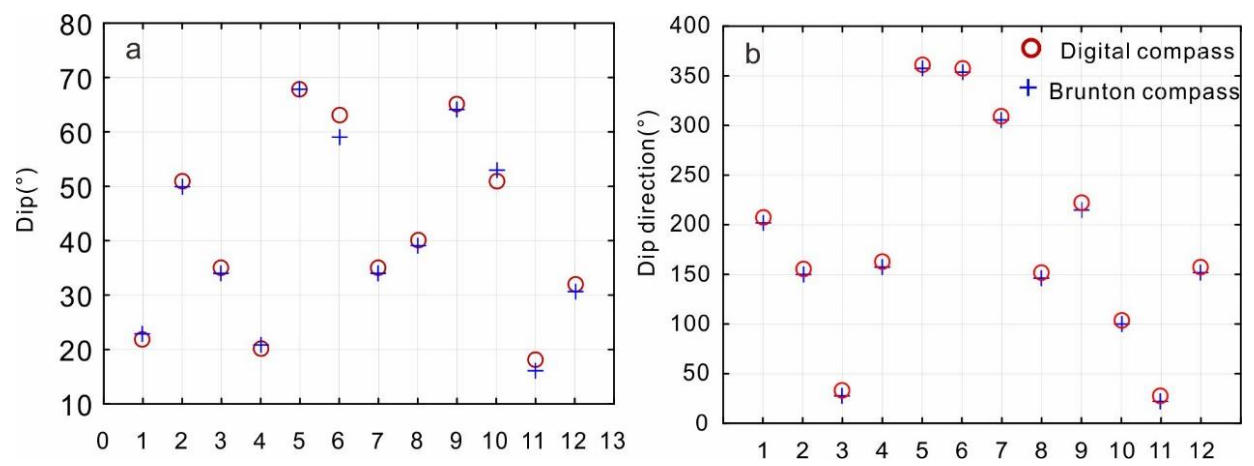

Figure 7. Comparison between a digital compass and a Bruton compass.

\subsection{Geological Mapping Result at the Zhoukoudian Area by Undergraduates}

Most field data collection systems are solely focused on data collection, while data post-processing and map-making depend on commercial GIS software. In the commercial GIS software, there is no customized module for processing the data collected in the field. Using common modules to make a geological map based on the collected data is timeconsuming. After the field data collection by the AoRGMAP, the DGSS also provides a powerful desktop platform of DGSInfo for data integration, map-making, and data sharing.

First, a group of five undergraduates collected the field data in the form of geological survey routes (Figure 8b,c) in areas A and B (Figures 1 and $8 a$ ). After field data collection, they imported the data from the PDA into the DGSInfo platform and built a PRB database including multiple geological routes. Based on the PRB database, geological boundaries were drawn through the same $B$ lines according to the strike of the strata layer and $V$ shaped rule (Figure 5a). In the process of drawing the geological boundaries, the DGSS ensures that the different boundary lines intersect to facilitate later processing. Spatial analysis was employed to cut off the geological boundaries and remove the micro-short line at the intersection points. Then, topological processing was used to create a new polygon layer of geological bodies. The properties of geological bodies can be obtained from the $\boldsymbol{R}$ and $\boldsymbol{B}$ lines based on the toolbox (Figure 5b) through spatial analysis. In this way, a primitive map (Figure 8) was produced, which provided a basis for making thematic geological maps (e.g., structure outline map) at different scales.

The geological mapping results are shown in Figure 8b,c. Compared to the geological map produced by professional geologists, the geological mapping results represent the geological framework, such as the symmetrical distribution of strata in the fold area (Figure $8 b$ ). In the details, there are some differences, such as the distribution of the Shihezi Formation $\left(\mathrm{P}_{2} s h\right)$ (Figure $\left.8 \mathrm{~b}\right)$ and Cambrian strata (Figure $8 \mathrm{c}$ ). The detailed differences are caused by the geological survey method. The method used in the field practice of the undergraduates was mainly based on the geological route through the main strata and geological framework. Due to the forest cover and steep ridges, the geological survey was not carried out along the geological boundary due to safety reasons. Nevertheless, it can be seen that the undergraduates mastered the skills of geological survey and geological map-making. 

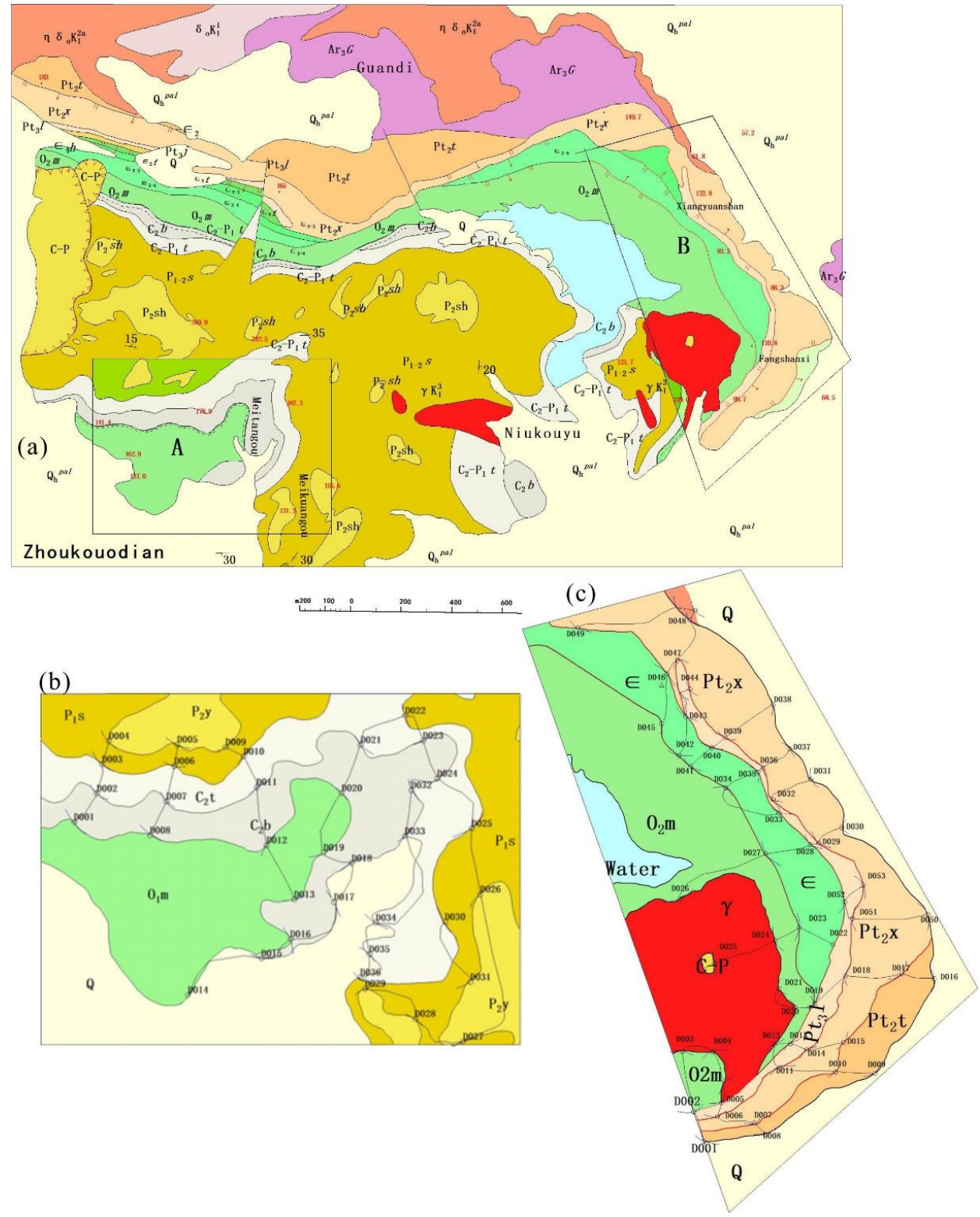

Figure 8. A comparison of geological mapping results between professional geologists and the undergraduates. (a) the geological map created by professional geologists. (b) a primitive geological map in the fold development area of A created by undergraduates, (c) a primitive geological map in the fault development area of $B$ created by undergraduates.

\subsection{Geological Cross-Section Survey}

The geological cross-section is located on the south slope of Taipingshan mountain (Figure 9a). In this cross-section, there are good outcrops along the mountain road and appropriate terrain for measuring geological cross-section. Data collection for the cross-section was conducted based on the Qmini A5 PDA. The orientation and distance of the transverse line were derived by the high-precision positioning system. The attitude of strata was obtained by the digital compass in the PDA. The cross-section data collected in the field were then inputted into the cross-section module in the DGSInfo to calculate the truth thickness of the strata and the apparent inclination. Based on the direct and derived parameters, the cross-section could be drawn on grid paper automatically (Figure 9b). A stratigraphic histogram could also be drawn based on the true thickness of the strata and the collected data in the field. 


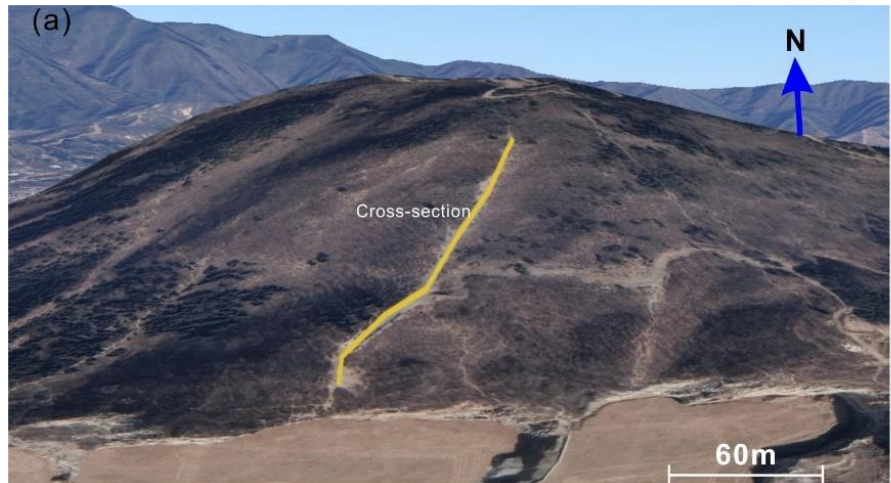

(b)

Geological Section of South Slope of Taipingshan

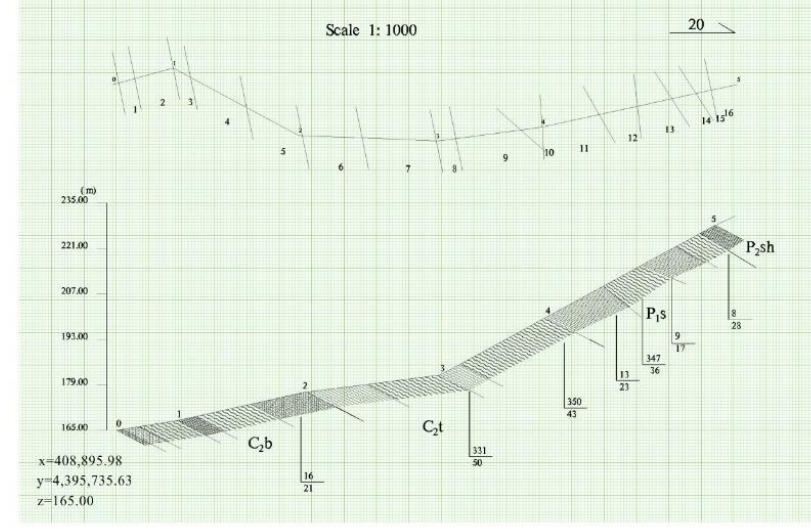

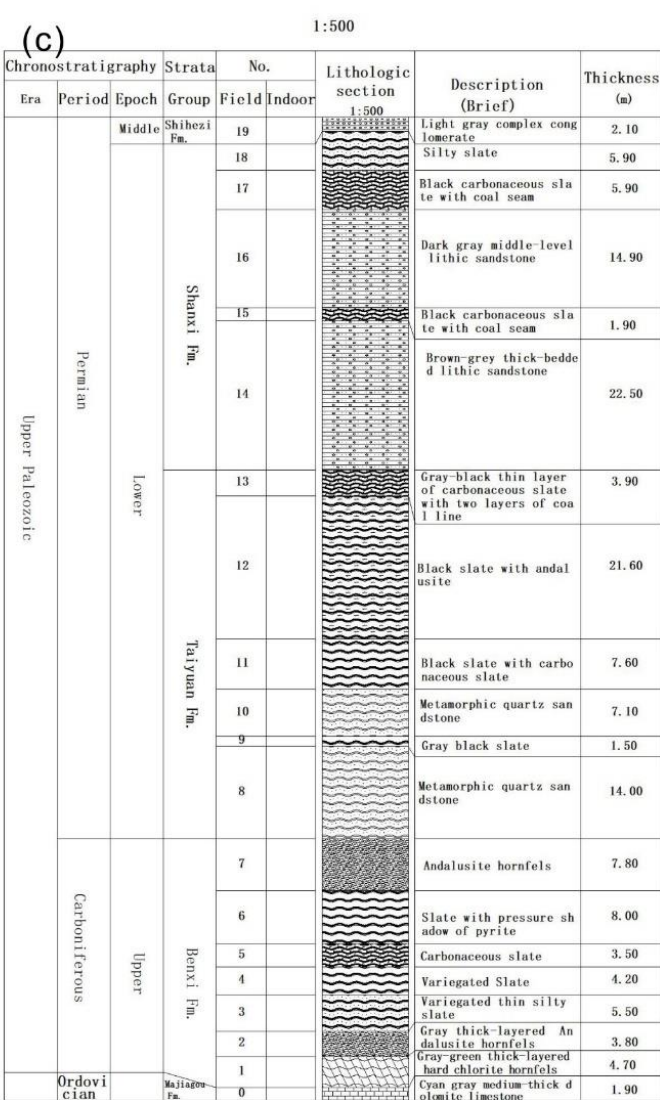

Figure 9. Geological cross-section data processed and map in DGSInfo. (a) the locality of cross-section in Taipingshan; (b) a geological section map automatically produced by DGSInfo; (c) a stratigraphic histogram automatically produced by DGSInfo.

Compared with the conventional method, the PDA-based geological section survey is efficient for data collection and producing cross-section maps. In terms of labor intensity, one undergraduate can use the PDA-based method to finish the data collection for a geological cross-section. The conventional method needs a team of 4-5 undergraduates to complete the same work. The time spent on this work is also powerful evidence to prove that the PDA-based method is more efficient. During field training, the undergraduates usually spend half of the day conducting the geological section survey. The PDA-based method, in comparison, only needs one and half hours. The automatic mapping technology for creating a cross-section map and stratigraphic histogram can also save a lot more time compared to the traditional hand drawing method.

\section{Discussion}

From the above overview of DGM systems and the examples of DGM application in Zhoukoudian, we can see that DGM is an efficient tool for field geological mapping and the corresponding education activities. Especially, the established workflow supports smooth data flow from field data collection to data integration and map making, which is a valuable aid to geoscientists comparing with the tedious manual work. In this section, a few topics related to the practical application of DGM in geological mapping and training are discussed.

\subsection{Experience of DGM-Supported Geological Training in Zhoukoudian}

Compared with indoor teaching, field geology teaching requests the instructors to master all kinds of knowledge about geological outcrops and have a clear memory of geological outcrops distribution in the field. However, this is difficult for young instructors who have only recently obtained their doctorate degrees. Although the DGSS (AoRGMAP 
and DGSInfo) was designed for geological mapping in the field, the functions can also be used in the preparation of geological field training. Before guiding students to the field, instructors can collect the spatial distribution of geological outcrops and some key teaching contents to store in the PDA with the AoRGMAP. During field teaching, the instructors can use the prepared data to search for teaching points and guide the undergraduates through the whole route and thus avoid missing teaching points and teaching contents.

Spatial geographic information can help undergraduates to understand geological structures and the distribution of geological bodies. Due to complex survey routes with varied directions of travel in the field, undergraduates are likely to lose their sense of direction, which will negatively influence their geological observations and understanding. For instance, the reappearance of strata in a geological survey route usually indicates the occurrence of a fold or fault. The survey route in Zhoukoudian has a hairpin turn near the teaching point D06 (Figure 10). Most of the time, the reappearance of strata (dashed line in Figure 10) is difficult for undergraduates to understand. They regard the reappearing strata as a fold wing that is symmetric with the first appearance of the strata. The moving track helps undergraduates understand that the reappearance is caused by the extension of the same strata rather than a fold or fault structure.

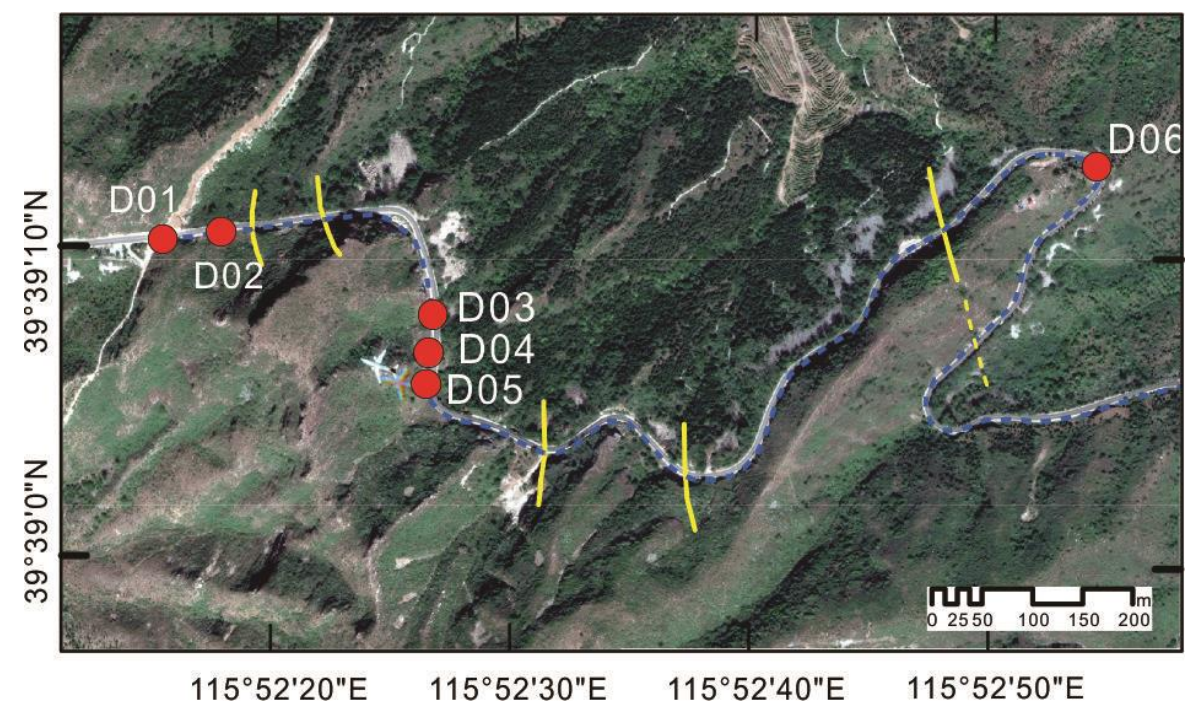

Figure 10. The geological teaching route with strata reappearance along the mountain road.

\subsection{Students' Feedback on DGM for Field Geology Training}

Field learning is a necessary component for students in geoscience majors and has a positive influence on improving the cognitive benefits of contents learned in the classroom, as well as providing transferable, technical, and social skills [33,41-43]. Knowledge of mineralogy, petrology, geological structures, surveying, stratigraphy, and paleogeography needs to be used flexibly in the practice training of field geology. DGM has initiated great changes in the industry in terms of data collection, processing, and storage. Industrial applications of DGM have also promoted the innovation of field teaching. However, there is controversy over whether DGM should be used in practical training of field geology. Although some field teaching experiences have proven that DGM has a positive influence on field geological learning of undergraduates $[30,43]$, some field geologists think that the practical training should be focused on geological cognition. To explore the influence of DMG on undergraduates during the field practice, a feedback survey was conducted among undergraduates participating in the geological practices in Zhoukoudian.

The feedback from the undergraduates also supports a positive view. More than $80 \%$ of the undergraduates thought that the PDA either has no influence on field observation or has a positive influence on field observation, which may be caused by the better portability and handleability of the PDA than that of the conventional toolbox (Table 2). In terms 
of time, the PDA is more convenient than the heavy toolbox and can save more time for field observation. A particular debate point is whether DGM reduces hands-on abilities and skills, such as drawing geological sketches. AoRGMAP imitates the process of paperbased geological mapping, and it provides three ways of drawing a sketch map: photo, vector, and grid methods. DGM does not change the core processes of geological training and mapping. It does, however, updates the medium for data storage and uses faster data collection and processing methods in the workflow. Our survey showed that the undergraduates preferred the PDA device to the paper-based toolbox (Figure 11a).

Table 2. Undergraduates' feedback on the influence of the PDA on field observation.

\begin{tabular}{ccc}
\hline Option & Number & Proportion \\
\hline Strong negative & 3 & $7.89 \%$ \\
Negative & 4 & $10.53 \%$ \\
No influence & 4 & $10.53 \%$ \\
Positive & 19 & $50.00 \%$ \\
Strong positive & 8 & $21.05 \%$ \\
\hline
\end{tabular}

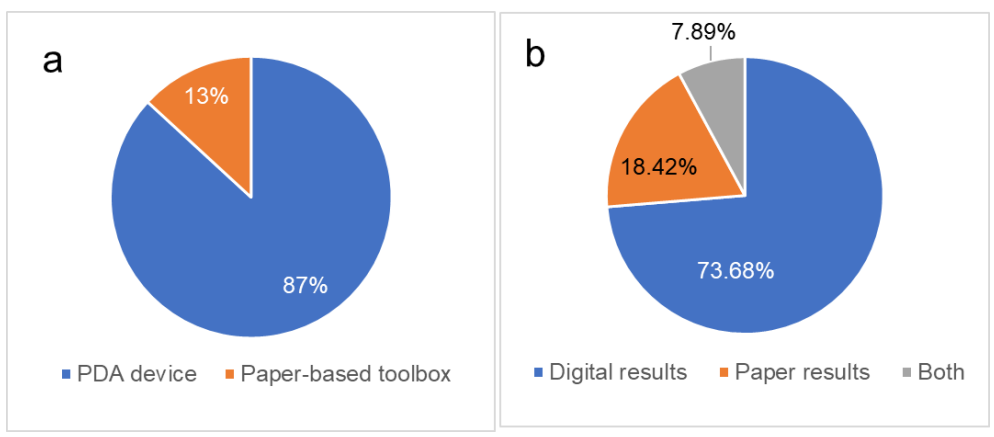

Figure 11. Undergraduates' preferences regarding the DGM system and conventional toolbox in field geology survey. (a) The preference between PDA device and paper-based toolbox; (b) the preference on methods for result production: digital map or paper map.

In the later stage of paper-based geological mapping, undergraduates spend a large amount of time on the repetitive tasks of drawing the geological boundaries, filling the legend pattern of geological units, and coloring the geological bodies on the tracing paper. In contrast, the DGM system can address this issue because all the data are stored in a digital form, and the mistakes can be modified at any time; thus, reworking the whole process can be avoided, which saves time. The feedback from the undergraduates indicates that they have a strong willingness to use the DGM system instead of the paper-based method in the workflow of data collection, processing, and map-making (Figure 11b). In the industry of geology and mineral exploration of China, a DGM system is required for data collection, map-making, and geological database construction in regional geological and mineral exploration surveys. Industry also requires graduates to master the skill of DGM. The preferences of both students and the industry development indicate geological education and geological field training should not stick to the conventional method.

The feedback also showed an unexpected interest of the undergraduates. Before the field practice in Zhoukoudian, there was an indoor training session on DGM for the students. The training was designed to guide the undergraduates to use the DGM system. However, in addition to the basic operation and data compilation, the undergraduates also had a strong interest in the data structure of the DGM system (Table 3), which indicates that students in the major of geology are also willing to learn the basics of data and information (i.e., geoinformatics) in the big data era. 
Table 3. The interests of undergraduates related to DGM.

\begin{tabular}{ccc}
\hline Option & Number & Proportion \\
\hline $\begin{array}{c}\text { Data structure of DGM } \\
\text { Basic operation of line, point and } \\
\text { polygon }\end{array}$ & 31 & $81.58 \%$ \\
$\begin{array}{c}\text { Projection parameters and } \\
\text { geologicla ajustment }\end{array}$ & 18 & $47.37 \%$ \\
Field data collection & 24 & $63.16 \%$ \\
$\quad$ Data import & 16 & $42.11 \%$ \\
Comiplition of geological map & 17 & $44.74 \%$ \\
\hline
\end{tabular}

\subsection{Future Development of DGM in Practical Training}

The students' feedback gives instructors a message on how to update the field teaching content and teaching methods and to strengthen the role of DGM in field training. In addition to the needs and interests reflected in the students' feedback, the fast-growing big data techniques, cloud service, and online course environment also bring great challenges and opportunities for the application of DGM in Zhoukoudian.

At this stage, the field data collection system and the map-making system are standindependent systems. AoRGMAP and DGSInfo are deployed on different devices. The data sharing and integration depend on the storage device, e.g., USB flash drives, which are inconvenient for instructors to check students' work. Therefore, there is a need to build a teaching cloud platform that can integrate cloud storage and service, smart cloud terminal, and the online course and cloud desktop. The cloud storage and service could be designed as synchronous storage of several parts, such as geological data collected in the field, field security monitoring of students, student work submission and result exhibition. The smart cloud terminal would be the PDA with the AoRGMAP data collection system. An online course would provide a platform for instructors to post the teaching videos, slides, and other related teaching materials. It is also possible to build an interactive system on it for undergraduates to learn field geological mapping in a virtual reality environment. The cloud desktop would relate to the cloud storage and services, and provide data compilation functions similar to DGSInfo.

\section{Conclusions}

In this study, we presented a brief overview of DGM and gave details about the DGM application in field geology training at the Zhoukoudian site. The following conclusions can be drawn: (1) The DGSS is a powerful tool that provides a pipelined solution for field data collection, data integration, and map-making. It reforms the method for regional geological survey using the PRB model. (2) Application of the DGSS can save time and reduce labor intensity during field practice and was welcomed by the undergraduates. (3) The DGSS can be used not only for field data collection but also for auxiliary teaching to enhance students' understanding of geological outcrops.

Supplementary Materials: The following are available online at https:/ /www.mdpi.com/article/10 .3390/app11115041/s1. Table S1: The photos of typical geological outcrops in Zhoukoudian area; and at https: / / drive.google.com/open?id=1gVAPbXNyiB5z_Dct8QJYOPQxGrVOCdwP. (10 April 2021). App S1: The free softwares of AoRGMAP and DGSInfo developed by the Development and Research Center of China Geological Survey.

Author Contributions: Conceptualization, C.W.; methodology and software, C.W.; investigation, C.W.; writing-original draft preparation, C.W.; writing-review and editing, C.W., X.W. and J.C.; project administration, J.C.; funding acquisition, C.W. and J.C. All authors have read and agreed to the published version of the manuscript.

Funding: This research was funded by the National Key R\&D Program of China (2017YFC0601500, 2017YFC0601504), the National Natural Science Foundation of China (41902305; 41942039), the Natural Science Foundation of Hubei Province (2019CFB231), Fundamental Research Funds for the 
Central Universities, China University of Geosciences (Wuhan) (CUG190617) and Teaching Reform Project of China University of Geosciences (Wuhan) (G1320311904).

Institutional Review Board Statement: Not applicable.

Informed Consent Statement: Not applicable.

Data Availability Statement: The data presented in this study are available upon request from the corresponding author.

Acknowledgments: Thanks for the suggestions from Xiaogang Ma and Terry Pavlis, and the support for feedback survey from the 2017 undergraduates in the major of exploration engineering of mineral resources and teaching team of China University of Geociences (Wuhan).

Conflicts of Interest: The authors declare no conflict of interest.

\section{References}

1. Hendry, L. Britain's First Geological Map. Available online: https://www.nhm.ac.uk/discover/first-geological-map-of-britain. html (accessed on 5 April 2021).

2. Balestro, G.; Piana, F.; De Donatis, M.; Bruciatelli, L. Representation and transfer of geological knowledge in IT-supported projects. Ital. J. Geosci. 2010, 129, 441-449. [CrossRef]

3. Vanegas, A. Removing Science Workflow Barriers to Adoption of Digital Geological Mapping by Using the GeoMapper Universal Program and Visual User Interface. In Proceedings of the Digital Mapping Techniques '01, Tuscaloosa, AL, USA, 20-23 May 2001; Soller, D.R., Ed.; pp. 103-114.

4. Mookerjee, M.; Vieira, D.; Chan, M.; Gil, Y.; Pavlis, T.; Spear, F.; Tikoff, B. Field Data Management: Integrating Cyberscience and Geoscience. Eos 2015, 96, 18-21. [CrossRef]

5. Pavlis, T.L.; Langford, R.; Hurtado, J.; Serpa, L. Computer-based data acquisition and visualization systems in field geology: Results from 12 years of experimentation and future potential. Geosphere 2010, 6, 275-294. [CrossRef]

6. Rogers, D.; McCann, T.; Cooper, A. Integrating paper-based habitat mapping with mobile electronic field recording procedures. Ecol. Inform. 2010, 5, 479-483. [CrossRef]

7. Whitmeyer, S.J.; De Paor, D.G. Crowdsourcing Digital Maps Using Citizen Geologists. Eos Trans. Am. Geophys. Union 2014, 95, 397-399. [CrossRef]

8. Brown, K.D.; Sprinkel, D.A. Geologic Field Mapping Using a Rugged Tablet Computer. In Proceedings of the Digital Mapping Techniques '07-Workshop Proceedings, SC, USA, 20-23 May 2007; Books and Open-file Reports Section, U.S. Geological Survey: Reston, VA, USA, 2008; pp. 53-58.

9. Clegg, P.; Bruciatelli, L.; Domingos, F.; Jones, R.R.; De Donatis, M.; Wilson, R.W. Digital geological mapping with tablet PC and PDA: A comparison. Comput. Geosci. 2006, 32, 1682-1698. [CrossRef]

10. De Donatis, M. Earth and Environmental Sciences: Field classes with GIS/GPS and tablet PC. In Proceedings of the First International Workshop on Pen-Based Learning Technologies (PLT 2007), Catania, Italy, 4-5 May 2007. [CrossRef]

11. De Donatis, M.; Susini, S.; Delmonaco, G. Digital geologic mapping methods: From field to 3D model. Int. J. Geol. 2008, 2, 47-52.

12. De Donatis, M.; Antonello, A.; Antonello, A.; Susini, S.; Susini, S. BeeGIS: A new open source tool for mobile GIS applications. Rend. Online Soc. Geol. It 2008, 3, 1-3.

13. Jones, R.R.; McCaffrey, K.J.W.; Clegg, P.; Wilson, R.W.; Holliman, N.S.; Holdsworth, R.E.; Imber, J.; Waggott, S. Integration of regional to outcrop digital data: 3D visualisation of multi-scale geological models. Comput. Geosci. 2009, 35, 4-18. [CrossRef]

14. Jones, R.R.; McCaffrey, K.J.W.; Wilson, R.W.; Holdsworth, R.E. Digital field data acquisition: Towards increased quantification of uncertainty during geological mapping. Geol. Soc. London Spec. Publ. 2004, 239, 43-56. [CrossRef]

15. Jordan, C.J.; Napier, B. Developing digital fieldwork technologies at the British Geological Survey. Geol. Soc. London Spec. Publ. 2016, 436, 219-229. [CrossRef]

16. Oriel, S.S.; Gabrielse, H.; Hay, W.W.; Kottlowski, F.E.; Patton, J.B.; De Vito, S. North American Stratigraphic Code. AAPG Bull. 1983, 67, 841-875.

17. Wright, B.E.; Stewart, D.B. Digitization of a Geologic Map for the Quebec-Maine-Gulf of Maine Global Geoscience Transect; Books and Open-file Reports Section, U.S. Geological Survey: Reston, VA, USA, 1990.

18. Williams, V.S.; Selner, G.I.; Taylor, R.B. GSMCAD a New Computer Program that Combines the Functions of the GSMAP and GSMEDIT Programs and Is Compatible with Microsoft Windows and ARC/INFO; Books and Open-file Reports Section, U.S. Geological Survey: Reston, VA, USA, 1996.

19. Blewett, R.; Hazell, M. User's Guide to MapPad and AGSO FIELDPAD for the Apple Newton Palmtop Computer; Australian Geological Survey Organisation: Canberra, Australia, 1997.

20. Brodaric, B. The design of GSC FieldLog: Ontology-based software for computer aided geological field mapping. Comput. Geosci. 2004, 30, 5-20. [CrossRef]

21. Briner, A.P.; Kronenberg, H.; Mazurek, M.; Horn, H.; Engi, M.; Peters, T. FieldBook and GeoDatabase: Tools for field data acquisition and analysis. Comput. Geosci. 1999, 25, 1101-1111. [CrossRef] 
22. Broome, J.; Brodaric, B.; Viljoen, D.; Baril, D. The Natmap Digital Geoscience Data-Management System. Comput. Geosci. 1993, 19, 1501-1516. [CrossRef]

23. Geometry Getting Started: Capturing Data with iGIS. Available online: https://www.geometry.com.au/igis/getting-startedcapturing-data-with-igis/ (accessed on 5 April 2021).

24. Li, C. Guide of Digital Geological Survey System; Geological PublishingHouse: Beijing, China, 2011.

25. Li, C.; Yang, D.; Li, F.; Liu, C.; Liu, X.; Yu, Q.; Lv, X. Basic framework of the digital geological survey system and applicaiton of its kye technology. Geol. Bull. China 2008, 27, 923-944.

26. Qingwen, Y.; Li, C.; Kexin, Z.; Donglai, Y.; Yunhai, Z.; Mengchun, G. Digital geological mapping and its development. Earth Sci. China Univ. Geosci. 2003, 28, 370-376.

27. Liu, G.; Wu, C.; Wang, X. Researchprogressof field working system of computer-aided regional geological survey. Adv. Earth Sci. 2003, 18, 77-84.

28. Vaughan, A.; Collins, N.; Krus, M.; Rourke, P. Recent development of an earth science app-FieldMove Clino. In Proceedings of the EGU General Assembly Conference Abstracts, Vienna, Austria, 27 April-2 May 2014; p. 14751.

29. Walker, J.D.; Tikoff, B.; Newman, J.; Clark, R.; Ash, J.; Good, J.; Bunse, E.G.; Möller, A.; Kahn, M.; Williams, R.T.; et al. StraboSpot data system for structural geology. Geosphere 2019, 15, 533-547. [CrossRef]

30. Lundmark, A.M.; Augland, L.E.; Jørgensen, S.V. Digital fieldwork with Fieldmove-How do digital tools influence geoscience students' learning experience in the field? J. Geogr. High. Educ. 2020, 44, 427-440. [CrossRef]

31. Whitmeyer, S.J.; Atchison, C.; Collins, T.D. Using mobile technologies to enhance accessibility and inclusion in field-based learning. GSA Today 2020, 30, 4-10. [CrossRef]

32. Oliinyk, M.; Bubniak, I.; Vikhot, Y. Using Move software by geological field works. Int. Conf. Young Prof. 2021, 1-5. [CrossRef]

33. Whitmeyer, S.J.; Pyle, E.J.; Pavlis, T.L.; Swanger, W.; Roberts, L. Modern approaches to field data collection and mapping: Digital methods, crowdsourcing, and the future of statistical analyses. J. Struct. Geol. 2019, 125, 29-40. [CrossRef]

34. Bowers, D.S. Augmented reality smartphone compasses: Opportunity or oxymoron? In Adjunct Proceedings of the 2019 ACM International Joint Conference on Pervasive and Ubiquitous Computing and Proceedings of the 2019 ACM International Symposium on Wearable Computers, London, UK, 9-13 September 2019; pp. 13-16. [CrossRef]

35. Liu, G.; Wang, X.; Zhao, W.; Wu, C.; Ouyang, J. The development of computer-aided regional geological mapping system and field practice teaching reform for base class. Chin. Geol. Educ. 2001, 3, 32-35.

36. Lang, X.; Wang, G.; Wei, Y.; Xu, D.; Li, J. Problems and Solutions of the Application of "Digital Geological Mapping" in Practice Teaching of Universities of Geosciences. Chin. Geol. Educ. 2017, 26, 54-59.

37. Takegami, M. The origins of modern geology in China: The work of DJ Macgowan and R. Pumpelly. Zinbun 2016, 46, $179-197$.

38. Liu, B.; Ba, J.; Zhang, L.; Nengsong, C.; Xiaoyan, L.; Zejun, Z.; Yanming, Y. Zircon LA-ICP-MS U-Pb Dating of Metamorphism and Anatexis of the Guandi Complex, Zhoukoudian Area, Beijing. Geol. Sci. Technol. Inf. 2008, 27, 37-42.

39. Li, C.; Qingwen, Y.; Donglai, Y.; Lihua, Q.; Yunhai, Z.; Mengchun, G. Research on PRB digital mapping techniques. Earth Sci. China Univ. Geosci. 2003, 28, 377-383.

40. Hong, L.I.U.; Lijian, W.A.N.; Yaying, L.U. High precision positioning technology for long distance ocean engineering based on BeiDou Satellite Navigation System. Bull. Surv. Mapp. 2017, 62-66. [CrossRef]

41. Henry, T.; Murray, J. How does it feel? The affective domain and undergraduate student perception of fieldwork set in a broad pedagogical perspective. Tuning J. High. Educ. 2018, 5, 45-74. [CrossRef]

42. Mogk, D.W.; Goodwin, C. Learning in the field: Synthesis of research on thinking and learning in the geosciences. Spec. Pap. Geol. Soc. Am. 2012, 486, 131-163. [CrossRef]

43. Senger, K.; Nordmo, I. Using digital field notebooks in geoscientific learning in polar environments. J. Geosci. Educ. 2020, 69, 166-177. [CrossRef] 